\title{
Justice in the Social Distribution of Health
}

\author{
Johannes Kniess ${ }^{1}$ \\ Princeton University \\ 迆niess@princeton.edu
}

\begin{abstract}
How should think, from the point of view of distributive justice, about inequalities in health and longevity? Norman Daniels's influential account derives a social duty to reduce health inequalities from Rawls's principle of fair equality of opportunity. This paper criticises Daniels's approach and offers an alternative. To the extent that the basic structure of society shapes people's opportunities to be healthy, we ought to think of 'the social bases of health' directly as a Rawlsian primary social good. The paper attempts to clarify the correct principle for its distribution, and its relationship to other goods that give rise to considerations of justice.
\end{abstract}

\section{Keywords}

Health inequalities; social determinants of health; Norman Daniels; John Rawls; primary social goods; indexing problem

\section{Introduction}

In this paper I attempt to show how health should figure into our thinking about distributive justice. Though I understand the latter broadly within the framework of John Rawls's theory, I hope also to say something more general about why egalitarians

\footnotetext{
${ }^{1}$ Many thanks to Gabriele Badano, Dan Iley-Williamson, Robert Van't Hoff, Fred Zaumseil, and especially Norman Daniels, Cécile Fabre and David Miller for generous written comments and helpful conversations. I should also like to thank audiences at Manchester, Oxford and Warwick, as well as three anonymous reviewers for Social Theory and Practice.
} 
should value health, and how it compares and relates to other important goods that give rise to considerations of distributive justice.

The practical relevance of this topic derives from the vast social inequalities in health and longevity that we observe in all contemporary societies. To take but one example, it is reported that women in Manchester can expect to live only 54.4 years in good health, compared to over 72 years for women in the London Borough of Richmond. ${ }^{2}$ This might seem an extreme figure for a wealthy country like the UK, yet it has been known for some time now that inequalities in mortality and morbidity are pervasive in both developed and developing countries. ${ }^{3}$ How are we to think, from the point of view of justice, about these health disparities? Are they different from inequalities in other dimensions, say, in income or wealth?

Let me begin by sketching a widespread view regarding the value of health. Throughout history, the notion that health is 'special' has enjoyed considerable popularity. The ancient philosopher Epicharmus of Kos thought that health is 'the best thing a man can have.' Around two thousand years later, René Descartes agreed it is 'without doubt the first good and the foundation of all other goods in life." And even today, perhaps unsurprisingly, many people continue to think of health as something of the utmost importance. Consider the gap in healthy life expectancy between women in Manchester and Richmond: many ordinary people who find nothing objectionable about large inequalities in income or wealth would presumably be shocked about this sort of inequality. ${ }^{5}$ Does this indicate that health is somehow more important than other goods? If so, should we be more concerned about inequality in this domain?

\footnotetext{
2 Office for National Statistics 2016: 3.

3 Two landmark studies in the UK context are the 'Whitehall Studies' (1967-1977) and the 'Black Report' (1980), Marmot 2004; Black 1990.

${ }^{4}$ Freeman 1971: 37; Descartes 1637, cited in Anand 2004: 17.

${ }_{5}$ Cf. Daniels 2008: 18.
} 
Unfortunately, theorists of justice have traditionally not devoted much attention to these questions. Or to be more precise, they have focused rather narrowly on one part of the problem, namely the value and distribution of medical resources. Some authors have attempted to provide normative justifications for the universal provision of basic healthcare. Many others have written on how to allocate scarce healthcare resources fairly. ${ }^{6}$ The importance of these issues is undisputed. And yet, they leave unaddressed a more general question concerning the social distribution of health itself, rather than just healthcare: when is it fair that some individuals or social groups live longer, healthier lives than others?

I say that this question is more general because there are many factors that influence how healthy we are, and at least in high-income countries, healthcare does not seem to figure among the most important ones. There is, after all, a universal National Health Service in both Manchester and Richmond. Recent empirical research leaves little doubt that health disparities are primarily a product of the 'social determinants of health,' the socially alterable factors outside the traditional healthcare system, which, independently of their effect on access to healthcare, affect individual health levels. These determinants include, among other things, income, education, housing and social status. ${ }^{7}$ So we might be interested in a fair distribution of healthcare for many reasons, but if we are interested in inequalities in health, we must pay close attention to all socially alterable determinants of health.

In this wider sense, the problem of justice in the social distribution of health has traditionally been a rather neglected area of inquiry in political theory. The most important exception is found in the work of Norman Daniels. Since the 1980s, Daniels

\footnotetext{
${ }^{6}$ E.g. Dworkin 2000; 1993; Buchanan 1984; Kamm 1993; Daniels and Sabin 1997.

7 Marmot and Wilkinson 1999; Birn 2011; WHO Europe 2003.
} 
has attempted to incorporate a concern for health into Rawls's theory of justice, focusing on healthcare in his earlier work, but later broadening his approach to deal with the distribution of health proper. His elegant theory-which explains the value of health through its instrumental importance for fair equality of opportunity—has rightly turned him into a key figure in the debate. To paraphrase a famous critic of Rawls, everyone interested in justice in health must either work within Daniels's theory or explain why not.

My strategy in this paper is the following. The first part is mostly critical: I argue that there are good reasons not to work within Daniels's theory. This is mainly because, despite its many virtues, the argument is problematic as an extension of Rawls's theory. In section 3, I put forward the outline of an alternative approach to justice in the distribution of health. Much like Daniels's work, it operates within the framework of Rawls's theory, justice as fairness. Unlike it, it locates the value of health more directly: given that our health prospects are deeply shaped by the basic structure of society, we can treat what I call the 'social bases of health' as a Rawlsian 'primary social good.' This raises the question of how this good relates to other primary goods, such as income and wealth. In section 4, I resist the view that health is 'special,' arguing instead that its promotion does not enjoy priority over the promotion of other goods governed by Rawls's difference principle. Without clear priority rules, however, we are confronted with an indexing problem whenever disparate goods conflict. I argue in section 5 that in cases like these, democratic processes must show the way. Finally, section 6 summarises my views and highlights the contrasts between Daniels's account and mine. 


\section{Rawls and Daniels}

Rawls never wrote much about the problem of health inequalities. In the Theory of Justice, parties to the 'original position' are idealised as 'normal and fully cooperating' over a complete life, so that health becomes a 'problem of extension,' something to be dealt with at the legislative stage. ${ }^{8}$ What motivated this position? Why didn't Rawls regard health as a benefit (and disease as a burden) subject to the principles of distributive justice that ought to regulate a scheme of social cooperation? The answer, I think, lies in Rawls's fundamental insight that justice concerns 'the basic structure of society, or more exactly, the way in which the major social institutions distribute fundamental rights and duties and determine the division of advantages from social cooperation." In such an institutional theory, justice concerns the effects of the basic structure on our ability to pursue our individual life plans. This in turn is measured by and achieved through the distribution of 'primary social goods:' basic liberties, opportunities and powers, income and wealth, and the social bases of self-respect. Other goods, such as health or intelligence, do not raise the issue of distributive justice for Rawls because they are, in his view, 'natural goods; although their possession is influenced by the basic structure, they are not so directly under its control. ${ }^{, 10}$

This is not to say that Rawls thought illness and disability unimportant. As his critics pointed out, if those with severe health problems were not somehow entitled to a greater share of resources, they would be implausibly disadvantaged vis-à-vis healthy people. ${ }^{11}$ The medical costs of a serious chronic condition could simply deprive them of the resources to pursue their own life plans. In response, Rawls acknowledged a

\footnotetext{
8 Rawls 1999b: 368.

${ }^{9}$ Rawls 1999a: 6.

10 Ibid.: 54, emphasis added.

11 Arrow 1973; Sen 1980.
} 
need to explore 'whether justice as fairness can be extended to provide guidelines for these cases; and if not, whether it must be rejected rather than supplemented by some other conception. ${ }^{12}$ Yet this raised the question of how a concern for medical needs could be reconciled with the fundamental insight that distributive justice concerns only the benefits and burdens of social cooperation, as opposed to natural goods.

The most elegant solution to this problem was put forward by Norman Daniels. His core argument ran as follows:

(P1) Healthcare protects health, understood as the absence of disease. ${ }^{13}$

(P2) Health, in turn, is an important pre-condition for the pursuit and realisation of valued life plans.

(P3) Justice requires fair equality of opportunity to pursue valued life plans.

(C) Therefore justice also requires the provision of universal healthcare.

At (P3), Daniels's argument rests on a subtle reinterpretation of Rawls's principle of fair equality of opportunity. In Rawls's theory, the principle is meant to guarantee fair opportunities to access offices and positions of responsibility. Yet while it is true that being reasonably healthy will contribute to a successful career, Daniels wants to show that justice requires meeting the health needs of everyone, including those who are not competing for positions. Therefore the opportunity principle is broadened to cover not only jobs, but more generally what he calls a fair share of the opportunity range: 'the array of life plans reasonable persons [in a given society] are likely to construct for

\footnotetext{
12 Rawls, 2001a: 176n.

${ }^{13}$ Daniels (1985: 28) follows John Boorse in understanding diseases as 'deviations from the natural functional organization of a typical member of a species'.
} 
themselves,' given their talents and skills. ${ }^{14}$ For instance, infertility is a medical pathology that doesn't affect one's chances when applying for a job, yet it prevents people from pursuing their life plan of having children. It follows from Daniels's broadened notion of opportunity that if there is a cure for infertility, justice would require us to provide it.

Not only does the argument tease out an implication of justice of fairness that Rawls himself had not foreseen, namely a requirement to provide universal healthcare. It also captures the widespread idea that health is a particularly important good. This is expressed by the egalitarian character of the opportunity principle, and its lexical priority over the difference principle in Rawls's theory: whereas the former demands equal chances for equally talented people, the latter permits inequalities so long as they work to the greatest benefit of the worst-off. To put it differently, there is now a strong case for an equal claim to have opportunity-limiting health problems redressed, even whilst there might be permissible inequalities in income and wealth. Daniel's theory is thus a modern version of the claim that health is 'special,' i.e. to be treated differently and separately from other social goods.

Many, including perhaps Rawls himself, ${ }^{15}$ found this to be a convincing extension of justice as fairness. Yet as it became increasingly clear that healthcare is neither the only, nor the most important determinant of health, Daniels began to revise his own argument. ${ }^{16}$ If healthcare has special moral importance because of its impact on opportunity, then the same must be true of all social determinants of health. It follows that justice as fairness requires an egalitarian distribution of both healthcare and the other social determinants. Incidentally, Daniels argues, Rawls's theory already provides a

\footnotetext{
14 Ibid.: 33.

15 See Rawls 1993: 184; 2001a: 174-5.

16 Daniels, Kennedy and Kawachi 2004; Daniels 2008.
} 
framework for the distribution of these socio-economic determinants of health. For instance, income and wealth are fairly distributed through the difference principle, education and healthcare are regulated by the principle of fair equality of opportunity, and political participation is guaranteed by the principle of equal basic liberties. Without any major modifications, then, Rawls's theory of justice would lead to high levels of fairly distributed population health. In short: 'justice is good for our health. ${ }^{, 17}$

With this move, Daniels manages to bring together healthcare and the social determinants under a single theory explaining the moral significance of health. He also embeds this rationale in Rawls's work, presenting a comprehensive theory of justice with impressive scope and depth. This has rightly turned it into the leading approach in the field, and as such it has naturally attracted a host of different objections, ranging from concerns that it neglects the health of those who are not actively pursuing a life plan, ${ }^{18}$ to worries about the international inequalities condoned by a society-relative 'opportunity range. ${ }^{19}$ These debates about the implications of Daniels's account are well known and I shall not revisit them here. I want instead to examine what we might call the internal structure of Daniels's argument. In particular, I want to provide two reasons for thinking that it does not fare well as an extension of Rawls's theory.

Let me begin with the idea of fair equality of opportunity. As we saw before, Daniels needs to broaden the notion of opportunity to ensure that those who are not competing for jobs (the retired, say, or those with severe cognitive disabilities) have their health needs considered under fair equality of opportunity. This may initially seem plausible, but it creates a problem if we want to hold on-as Daniels does- to the egalitarian logic of the opportunity principle, and its lexical priority over the difference

\footnotetext{
17 Ibid.: 6; Daniels et. al. 1999.

18 See e.g. Stern 1981: 341; Segall 2009: 32-3

19 Venkatapuram 2011: 226-7.
} 
principle. For, as I now want to argue, these features are logical consequences of the narrow focus on offices and positions of responsibility. To see why this the case, we need to understand Rawls's original motive for introducing the opportunity principle.

Primary goods have different functions and modes of distribution. Basic liberties, Rawls thought, protect such fundamental interests that the parties in the original position would ensure that they are equally distributed, and exempt from trade-offs with any other goods. Opportunities also take a special place in that their regulation is lexically prior to that of goods such as income and wealth, even though they are distributed in a way that takes into account respective talents: equally qualified people ought to have equal opportunities to access important jobs. Why should this be the case? Rawls believed that otherwise, those excluded from important positions would be right in feeling unfairly treated by society. This is not only because of the external rewards attached to positions of responsibility, but because qualified applicants would be 'debarred from experiencing the realization of self which comes from a skilful and devoted exercise of social duties. They would be deprived of one of the main forms of human good. ${ }^{20}$

There is an interesting Aristotelian dimension to this explanation, but let us leave that to one side. What matters here is the following: the experience of exercising important social duties is potentially very meaningful to people, and we must decide how to distribute access to it. Since positions of responsibility are relatively scarce (we cannot all become judges or CEOs), the fair way to do so is to introduce competition, to wit, fair equality of opportunity. Note, then, that the primary rationale for competition is not efficiency. ${ }^{21}$ After all, we could perhaps render everyone better off by excluding

\footnotetext{
${ }^{20}$ Rawls 1999a: 73.

21 Ibid.
} 
certain groups from attaining positions of responsibility - and if the distribution of offices were regulated by the difference principle, presumably that is exactly what we should do. But this would be unfair towards the excluded, for the 'realization of self that these scarce positions enable could not be compensated through greater material gain. It is this particular concern for fairness which sets the principle of equal opportunities apart from the difference principle.

However, it is not clear that this specific rationale can be applied to the pursuit of life plans in general, as Daniels intends, since not all life plans have this scarce or competitive character. Having children, for example, is an important life plan for many people. But is an infertile person denied fair equality of opportunity if she is not provided a cure for her condition? Compare this situation with that of a young person who wants to become a judge, but whose application is hopeless because she will never enjoy the educational privileges of more well-to-do candidates. It is easy to see why the frustration of her life plan is unfair: in regulating access to a scarce good, society has allowed the rules of the game to be rigged. The same does not seem to be true of the infertile person, however. At most, we could say that society is failing to help her realise her personal conception of the good.

Now, to be sure, a liberal society must ensure that all persons be able to pursue their reasonable goals in life, whatever these may be, by providing them a fair share of social resources. But this is the general idea of justice as fairness as a whole, not one that ought to be governed specifically by the opportunity principle. The point of all primary goods and their regulative principles is to ensure that persons have a fair chance of forming, revising and pursuing their conceptions of the good. The priority of the opportunity principle, in contrast, is explained by the fact that one particular form of 
good cannot be provided to all, making fair competition the only way to ensure that everyone is treated with equal respect.

In brief: broadening the notion of opportunity comes at the cost of undermining the internal logic and lexical priority of the opportunity principle. That in itself is bad enough, given that the 'specialness' claim is derived from said lexical priority. But the structure of the theory becomes all the more tangled once we consider Daniels's more recent move to include the social determinants of health, alongside healthcare, among the requirements to protect fair equality of opportunity. Recall that these determinants include factors such as income or wealth. Hence, to say that protecting everyone's health requires a fair distribution of income and wealth is to say that these goods ought to be governed by the opportunity principle. But income and wealth are, of course, already governed by the difference principle. This is a problem, I now want to show, because the two principles follow different distributive rules.

To elucidate the point, it is important to be aware of the empirical relationship between inequalities in socio-economic status and health disparities. In the epidemiological literature, it is now widely accepted that health follows a social gradient. This means that every step up or down the socio-economic ladder comes with a gradual increase or decrease in health: the poor are less healthy than the rich, but even the rich are less healthy than the very rich. ${ }^{22}$ Which way does the relationship work? Do healthy people become richer, or does being rich improve our health? The evidence suggests that the effects of the latter are far more significant, for we can observe that people moving up the social ladder are typically less healthy than the people in their class of destination, and vice-versa. ${ }^{23}$

22 Marmot 2004; Black 1990; Wilkinson 1996.

23 Marmot 2004: 60. 
The upshot of this is that any inequality in income or wealth is likely to translate into inequality in health, even above a threshold of basic needs. For example, a person who earns $£, 50.000 \mathrm{pa}$ is statistically less healthy than one who earns $£, 75.000$, who in

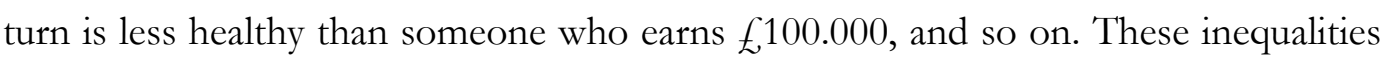
in income would be permissible under the difference principle, if they happened to work to the greatest advantage of the worst off (by producing economic incentives which lead to higher overall growth). Yet it seems that they would not be permissible under Daniels's version of the opportunity principle because they go together with opportunity-limiting inequalities in mortality and morbidity. And since the opportunity principle enjoys lexical priority over the difference principle, the conclusion seems to be that we ought not to tolerate them. In other words, the theory may be more egalitarian than Rawls intended.

This in itself would be an interesting outcome, but the problem is that Daniels does not want to follow the argument to its conclusion. Even though he acknowledges that the difference principle would lead to at least some avoidable inequalities in health, he is explicitly not committed to their removal. Instead, he maintains that Rawls's theory, without this more egalitarian twist, would flatten the socio-economic gradient as much as is reasonable to expect. In defence of this seemingly inconsistent position, Daniels claims that perfect equality in health (and therefore perfect equality of opportunity) is sometimes impossible. To drive the point home, he draws an analogy with another case where we do not insist on perfect equality of opportunity: the upbringing of children. As is well known, the family one is born in is a major determinant of the opportunities one faces in life. Despite this fact, Rawls does not advocate equalising opportunities by taking children from their parents and raising them in state-run foster 
homes. Daniels infers from this that 'even ideal theory does not produce perfect justice. Justice is always rough around the edges. ${ }^{24}$

The analogy is debatable, however. There may be weighty reasons to allow families to raise their own children; arguably it constitutes a fundamental right protected by Rawls's overarching principle of basic liberty. Is there a reason of comparable significance to tolerate the health inequalities in question? The only reason Daniels offers is the eschewal of greater prosperity which the economic incentives of the difference principle might generate. Yet not only is there not a basic right to the highest attainable level of income or wealth. There is also nothing obviously wrong or implausible in favouring a somewhat less prosperous society where there is more equality in health and longevity. If Daniels rejects this option, surely it must be because he believes that the distribution of income and wealth matter in themselves, and not only to the extent that they influence inequalities in health. A sensible view, admittedly, but one which seems to contradict his own theory about the special value of health, expressed through the lexical priority of the opportunity principle.

Let me summarise. I have so far argued that the internal structure of Daniels's theory is unstable in at least two regards. There is, first, a problem with the way a concern for health is subsumed under the opportunity principle, for the notion of opportunity that Daniels employs undermines the justification for said principle within Rawls's theory. With this revised notion, it is not clear that equality of opportunity should enjoy the lexical priority which in turn justifies the special moral importance of health. And indeed, dropping this lexical priority seems to be Daniels's only possible response to the second problem that we identified, regarding the regulation of the

24 Daniels 2008: 99. 
social determinants of health through the opportunity principle. But if that is his strategy, it is not clear what it means to say that health is 'special,' nor is it clear whether it is fair to abandon the lexical priority of the opportunity principle with regard to jobs and positions of authority. Hence Daniels's theory does not fit neatly within the Rawlsian framework he employs, and the core of the problem is his interpretation of the opportunity principle.

\section{An Alternative Reconstruction: Health as a Primary Good}

To say that Daniels's account is unconvincing as an extension of Rawls's theory is not to deny its many independent merits. In particular, the central insight that health is instrumentally valuable for the pursuit of our life plans is no doubt appealing, and I believe fundamentally correct, despite the difficulties we identified with Daniel's interpretation of the principle of fair equality of opportunity. And so, I would like in this section to offer an alternative reconstruction of a Rawlsian approach to justice in health; one which might avoid some of the pitfalls Daniels runs into, while at the same time salvaging some of his central ideas.

Rawls's theory, we said at the outset, offers an institutional view of justice. On this view, justice is concerned with the multiple ways in which basic social arrangements shape our opportunities to realise our personal life plans. Because the basic structure exerts such influence on our individual life prospects, it calls for regulative principles that could be justified to each member of the social system. At this point, as is well known, Rawls suggests that this justificatory burden could be met by the principle of 
equal basic liberties, the fair equality of opportunity principle and the difference principle. And as we just saw, Daniels argues that health enters the picture as one of the requirements to realise the second one of these principles.

However, it seems to me that health can also figure into our thinking about distributive justice at a more fundamental level. Health is not only important for fair equality of opportunity; it is in itself a reflection of the way the basic structure affects our life prospects. In other words, the social arrangements that we uphold have a significant impact on our individual opportunities to be healthy, as well as on the distribution of these opportunities across society. There are, of course, also natural determinants of health (to which I shall return shortly), but to the extent that health is substantially affected by the basic structure of society, its social distribution must be seen as a matter of distributive justice. Much like wealth or liberty, health must in some way or another count as one of the benefits of which society must ensure a fair distribution.

It might be worth clarifying this idea by contrasting it with a seemingly similar view which has been put forward in the literature. The notion that health matters insofar as it is shaped by social arrangements can be understood in two different ways. On a first interpretation, inequalities in health matter only when they reflect unjust social arrangements, where the justice of these arrangements is judged independently of their effects on health. Such an 'indirect approach' has been defended by Fabienne Peter, who insists that health inequalities are not unjust in themselves, but merely useful in 'understanding $[\ldots]$ how the organization of the basic structure of society affects people. ${ }^{25}$

25 Peter 2004: 103. 
The view that I set out to defend, in contrast, holds that the way in which an institutional order affects the health-prospects of its members can be unjust in its own right. That is, the distribution of health must figure among those features that make the basic structure of society just or unjust in the first place.

The best way to express this within Rawls's theory, I now want to argue, is to treat health directly as an object of distributive justice: as a primary social good. Rawls tells us that primary goods are 'things that every rational man is presumed to want. ${ }^{26}$ Whatever our particular plans in life, they provide all-purpose means to realise them. It is not hard to see why health is instrumentally valuable for the pursuit of our goals in precisely this way: it allows us to do the things that give meaning to our lives. To be sure, not every life plan requires full health to be realised. But the loss of longevity and health—both physical and mental—can restrict many of the projects that people may reasonably choose for themselves. Hence from the perspective of the parties in the original position, it would be rational to want health. Health is, perhaps, the paradigm case of something it would be rational to prefer more rather than less of.

Rawls seems to acknowledge these observations when he describes health as a primary good - albeit a natural one, one that is not directly under the control of the basic structure. But note that the empirical assumption underlying this latter view is wrong: in light of today's knowledge, we must view the basic structure as the principal determinant of population health. We know how different institutional designs affect the distribution of health in a population, and we can also tell who the winners and losers of particular arrangements will be. ${ }^{27}$ To the latter we should be able to explain why the arrangements that are in place work to their advantage.

\footnotetext{
${ }^{26}$ Rawls 1999: 54

27 Of course, I am not claiming that social epidemiology can predict with certainty the population health effects of particular institutional reforms. But the same is true of economics: we can only
} 
Yet presumably it is not just a misguided empirical belief which explains Rawls's reluctance to include health in his index of primary social goods. I think there is also another reason, although one which is never stated quite explicitly. The most intuitive way of conceptualising health is not as a resource, but as a constitutive element of welfare, a category Rawls rejects as a basis for interpersonal comparisons. Seen in this light, health does not seem to fit well with the other primary goods which we can distribute and re-distribute easily. It is this elusive nature of health that makes it much easier to focus on healthcare as a tangible social resource. Thus it is not surprising that whenever health has been considered as a primary social good, it has been in the form of medical resources and services. Ronald Green, for instance, suggests that a principle of equal healthcare would be chosen by Rawlsian contractors in the original position. In a similar vein, Robert Veatch proposes to govern healthcare directly by the difference principle. ${ }^{28}$

However: is it not health itself-rather than the means to restore it when it deteriorates - that we primarily have reason to want? While medical care can make all the difference for someone who is ill, it is often but the metaphorical 'ambulance waiting at the bottom of the cliff. ${ }^{29}$ Consider the health disparities between rich and poor people that can be observed in all societies. Granted, the poor would be even worse off if they had no access to medical care. Evidently more important, though, are the social conditions that lead to their poor health and short life-expectancy in the first place. If we attempted to close the health gap merely through the provision of more

give a rough indication of how a reform of property rights, say, might affect the overall distribution of wealth.

${ }^{28}$ Green 1976: 117; Veatch 1999.

${ }^{29}$ Daniels 2008: 79. 
or better healthcare for the poor, we might run into a form of 'bottomless pit ${ }^{30}$ problem without ever really achieving our aim.

The natural alternative, I would therefore argue, is to think of the social bases of health as a primary social good. ${ }^{31}$ We can here draw an analogy with another primary good, namely the social bases of self-respect. While self-respect is required for persons to advance their ends with self-confidence, it cannot be distributed directly. It can only be secured through a fair distribution of other goods, such as equal basic liberties and fair equality of opportunity. ${ }^{32}$ Something similar can be said about health: although the health of one person cannot literally be transferred to another, a more egalitarian distribution of health can be achieved indirectly through the allocation of other social goods. As Daniels correctly points out, the social gradient in health could be flattened through a fair distribution of income and wealth, education (which is also required for fair equality of opportunity), and political participation (which is guaranteed by the basic liberties). The list might be expanded to include social determinants which are not covered by Rawls's primary social goods. For instance, one determinant which plays a prominent role in the empirical literature concerns working conditions, in particular control over one's workplace. ${ }^{33}$

In short, by including the social bases of health in the index of primary goods we work within a resourcist (as opposed to welfarist) framework, without adopting an unwarranted focus on healthcare. The proposal therefore seems a natural revision of

\footnotetext{
${ }^{30}$ Kenneth Arrow (1973: 251) was the first to point to a 'bottomless pit' problem if healthcare were to be governed by the difference principle: since medical interventions know in principle no upper cost limit, improving the position of the worst-off would drain all public resources, leaving nothing for the pursuit of other social goals.

${ }^{31}$ Cf. Wilson's (2009: 5-6) for a brief discussion of the idea.

32 Rawls 2001a: 200.

33 See e.g. Marmot 2004: 129. But note that here too, we might find support for a fair distribution of this determinant in Rawls's work: justice as fairness implies an egalitarian workplace to allow for a fair distribution of power and authority, as well as the social bases of self-respect (Rawls 2001a: Ch. 4).
} 
Rawls's theory. But while Rawls himself did not rule out an extension of his indexin fact, he seemed to consider his list 'provisional' ${ }^{34}$ — there might well be good reasons to proceed with caution. Daniels, echoing Rawls, raises two potential objections to an extension like the one I have just outlined. ${ }^{35}$ The first concerns the universal character of primary social goods. If the index is expanded with goods that some people find important, but others care little about, it risks ceasing to be an index for a shared political conception of justice. In other words, in overstepping an 'overlapping consensus' on what justice demands, we fail to respect the fact of reasonable pluralism in society. ${ }^{36}$

It seems to me that this objection has some merit, depending on how we define health. According to the WHO definition, for example, health is 'a state of complete physical, mental and social well-being and not merely the absence of disease. ${ }^{37}$ Such an expansive notion of health could indeed conflict with a commitment to value pluralism, for we might reasonably disagree about the meaning of 'complete social wellbeing' Yet it is not clear why a less expansive definition—such as the definition of health as the absence of disease, which Daniels himself endorses ${ }^{38}$ — would be contentious in this way. Although people might reasonably disagree about 'social well-being,' virtually everyone prefers less medical pathology.

The second objection is more challenging. Rawls's theory relies on the possibility of identifying and improving the position of the worst-off members of society. However, the more criteria we use to define the latter-i.e. the more elements are added to the index of primary goods-the harder this task becomes. One way to make things

\footnotetext{
34 Rawls 1999a: 348; Rawls 1993: 181-2.

35 Daniels 2008: 56-7; Rawls 1993: 182.

36 Rawls 1993: 182; see also Wilson 2009: 5.

37 WHO 2013b.

${ }^{38}$ Daniels 2008: 36-42. In fact, it is unclear how Daniels can postulate that as a primary good, health threatens to undermine a shared political conception, whereas as a requirement of one of the principles of justice it does not.
} 
simpler is to rank dimensions of (dis-)advantage in terms of their significance, and this is what Rawls does by introducing a lexical ordering of primary goods: basic liberties are more important than opportunities, just as opportunities are more important than income or wealth. But note that even in Rawls's original theory there is an unresolved indexing problem between income and wealth, power and authority, and the social bases of self-respect. ${ }^{39}$ Consider, for instance, the relationship between income and power. Assuming that hierarchically organised workplaces are more productive than democratic ones, we are faced with a trade-off between these goods. Who, then, is worse off: the worker with a larger income, but less power at the workplace, or the one for whom the opposite is true? Problems of this kind exist in Rawls's original theory, but the worry is that adding more goods to the mix might exacerbate them. ${ }^{40}$

Yet pointing to this possibility is not enough to rule out the social bases of health as an element of the index of primary social goods. For one thing, we cannot know at this stage whether the proposed addition in fact aggravates the indexing problem because we have said nothing so far about how the social bases of health relate to other primary goods. We might come to think, for example, that they should enjoy absolute priority over everything else. Improbable though it seems, this would give us a clear answer to the question of who the worst-off are: always those with the smallest share of the social bases of health.

But even if the indexing problem should indeed be aggravated by our proposaland as I concede below, this is in fact likely_dealing with the added theoretical complexity might just be the price to pay for a better theory of justice. There is no point to a theory, no matter how parsimonious and elegant, if it fails to capture fundamental

\footnotetext{
${ }^{39}$ Rawls 1999b: 80. See also Arneson 1990: 445; Daniels 2008: 57.

40 Cf. Wilson 2009: 5.
} 
features of the subject-matter it sets out to explain. And so, the relevant question at present should be whether the distribution of the social bases of health is indeed a genuine concern from the point of view of justice. How we will manage to theorise this is a different matter; should it not be possible from within Rawls's framework, we might well need to re-examine the theory as a whole. Thus, the indexing problem requires independent discussion, to which I will turn in section 5.

Beforehand, however, I would like to conclude this section by examining a final objection to the general conceptual approach sketched here. A critic might readily accept that health and longevity are shaped to a large degree by the basic structure of society, but insist that health is also partly determined by nature, making it an unsuitable candidate for the index of primary social goods. Now, this objection might be understood in either of two ways. First, it could be claimed that our conceptual approach is too broad because primary social goods must per definition be entirely socially created. Basic liberties, opportunities and income are prime examples. However, it is not true that the same applies to self-respect: our genetic dispositions may have a considerable effect on our sense of self-esteem. ${ }^{41}$ Thus, by talking of the social bases of self-respect, Rawls makes clear that justice is concerned only with how social institutions and practices affect us. Analogously, distributive justice is only concerned with the social determinants of health.

Yet if this is the case, it may be argued that our proposal is too narrow. Whereas a theory like Daniels's attempts to justify a concern for all health inequalities, it is not clear that the approach sketched here has the resources to do so too. Recall that for Daniels, the origin of a disease or disability is irrelevant as long as it results in a less-

${ }^{41}$ E.g. Greven et. al 2009. 
than-equal share of the opportunity range. In contrast, the origins of pathology do matter if we conceptualise the social bases of health as a primary good: it seems we are now only duty-bound to remove social, not natural obstacles to good health. The account I propose would thus only take care of health inequalities that originate in unjust social structures, and not those which stem from differences in genetic dispositions or natural deterioration throughout the life course. This may seem counter-intuitive because we commonly assume that there are strong social obligations to attend to all health needs, regardless of their aetiology.

However, it is important at this point to distinguish between a requirement to eliminate or reduce health disparities on the one hand, and a social duty to meet basic healthcare needs on the other. A genetic inequality between two people may not be objectionable in and of itself, at the bar of justice. But if someone falls below some relevant threshold of good health—for whatever reason—justice may well demand to have his or her medical needs met. As mentioned at the outset, many philosophers have argued that justice requires everyone to be given access to at least a basic tier of medical care. One may argue, for instance, that a just society ought to guarantee a right to basic healthcare that reflects the insurance choices that prudent citizens would make in an idealised health insurance market. ${ }^{42}$ Nothing we have said contradicts this or other ways to establish a right to have basic health needs met, even when these needs do not originate in unjust social arrangements.

It is nonetheless true that on my account, the removal of natural inequalities in health above some threshold specified by a right to healthcare is not required by justice.

\footnotetext{
42 Dworkin 1993. Other accounts are pluralistic, combining, for example, prudential and rights-based arguments (Buchanan 1984). The general point is that there are reasons for a just society to provide basic universal healthcare, and these reasons are independent from our duty to distribute the social bases of health fairly. As such, they also reaffirm the value of universal healthcare in light of the relatively greater impact that the social determinants have on our health (Cf. Sreenivasan 2014).
} 
This may strike some people as objectionable. But if the justice of an inequality depends on the mechanisms that bring it about—as we have been assuming throughout - then the case for being less tolerant of socially engendered inequality is hard to resist. The point is set out in great clarity by Thomas Nagel, who invites us to imagine that 10 per cent of the population suffer from a randomly distributed genetic defect which significantly reduces life expectancy. Is this state of affairs inherently unjust? Nagel doesn't think so: 'because it is nature that has dealt them this blow, a social system that does not engage in significant rectification of the inequality is not guilty of injustice. ${ }^{43}$ The example is 'fanciful and extreme,' but the point it makes seems to follow consistently from an institutional conception of justice. If a person's misfortune has purely natural causes, it cannot be our social institutions that have treated her unfairly. The genetic defect is hence akin to an earthquake or a meteorite crash: lamentable, but not unjust.

Although Nagel makes a valid theoretical point, in practice inequalities are rarely purely natural facts. More often than not, the natural features that make one person worse off than another are inextricable from the social arrangements that frame their relationship. This is perhaps best exemplified by the case of the disabled. As disability rights advocates have long argued, the disadvantage of a congenital mobility impairment has little to do with not being able to walk. The greater problem, in their view, lies rather with the inability to participate in an economy, and move in a built environment exclusively designed for the non-disabled. The general point here is that the way our social arrangements react to (and thereby shape the effects of) natural misfortunes must itself stand in need of justification. An earthquake may not be unjust. But if the

43 Nagel 1997: 315. 
resulting burden of death, disease and injury is disproportionately high among some social groups and not others, our social institutions may well be to blame.

All this suggests that the scope of our institutional theory is wider than might initially appear. For it is not enough to ensure a fair distribution of the direct effects of the basic structure on people's life prospects. There are further indirect effects in the way our social arrangements react to pre-institutional disadvantage, such as congenital conditions and natural medical needs. Consider, in particular, how people in different socio-economic positions may differ in their abilities to access curative and palliative care for these conditions. Put quite simply, a rich person with a chronic, congenital disease is much more likely to live a long life (through better access to medical care, etc.) than a poor person with the same condition. Even though the disease itself is outside the scope of justice, then, social differences in the ability to manage it are not. Society does not need to justify itself to those who suffer bad luck in the genetic lottery, but it must ensure that the basic structure doesn't compound their misfortune. ${ }^{44}$

\section{The Social Distribution of Health}

Thus far I have argued that a concern for health and health inequalities can be integrated into justice as faimess by treating the social bases of health as a primary social good. The question I want to ask now is this: given that different primary goods follow different distributive rules, how should the social bases of health be distributed? In

\footnotetext{
${ }^{44}$ There are, of course, limits to what a society is obliged to do with regard to what I have been calling the indirect distributional effects of the basic structure. For one thing, justice so understood merely demands neutralising these indirect effects, rather than compensating natural disadvantages with additional social resources to achieve something like overall equality in life prospects. Furthermore, even when social arrangements compound natural disadvantages, there are limits to how much our institutions can be reformed to eliminate these effects. As Dan Wikler (1978) has argued, for example, changing our legal system so that intellectually impaired people are not disadvantaged vis-à-vis people of average intelligence (say, by lowering the bar to enter and exit legal contracts) may involve intolerably high social costs.
} 
other words, we must now establish the distributive rule for the social bases of health - or health, as I shall say interchangeably for simplicity's sake. Since 'the correct regulative principle of anything depends on the nature of that thing, ${ }^{, 45}$ as Rawls memorably put it, we need to approach this task by asking what kind of good health is, why we value it, and how it relates to other items on the index of primary goods.

I want to suggest that our general question can in fact be divided into two. As will become clear, these two questions are deeply intertwined, and yet it might be instructive to approach them separately. The first concerns the distributive logic within the domain of health: should everyone enjoy the same level of health? If not, under what conditions are inequalities justified? Call this the internal dimension of the distributive question. The second question concerns the distribution of health in relation to other goods: can we ever compensate a shortfall in health with, say, more wealth? Or should health be a discrete sphere, nonfungible and detached? Call this the external dimension.

These two dimensions are often muddled together. Ronald Dworkin, for instance, assumes that those who consider health special must think that it is 'chief among all goods,' and that it should be distributed equally. ${ }^{46}$ However, it is important to point out that taking a position on one question does not necessarily commit one to a position on the other. For instance, one might hold that the distribution of health ought to be isolated as far as possible from that of other goods, thereby rejecting trade-offs, and yet choose among sufficientarian, egalitarian or other distributive principles within the sphere of health. Inversely, we might come to think that a prioritarian logic should govern health, yet this does not establish whether it should be lumped together with the other goods regulated by the difference principle. It may turn out, after all, that

\footnotetext{
${ }^{45}$ Rawls 1999a: 25.

${ }^{46}$ Dworkin 1993. Note that Dworkin is referring specifically to healthcare, but the point applies more broadly.
} 
improving the position of the worst-off with respect to health requires something different than improving the position of the worst-off with respect to wealth.

Let us then begin by considering first the internal dimension. The egalitarian impulse is to distribute goods equally, unless independent reasons tell in favour of inequalities. And so, our first assumption might be that the distribution of the social bases of health should follow a strictly egalitarian (or 'equalitarian') pattern. In practice this would mean that the institutional order should be designed so that no socially produced inequality in health is tolerated. But this, as we will now see, is quite a demanding position.

Among contemporary egalitarians, unqualified defences of equalitarianism are rare. Much of this has to do with the 'levelling down' objection: if strict equality is what we really cared about, we could simply reduce the position of the best-off to that of the worst-off, thereby making everybody worse off. ${ }^{47}$ To illustrate, imagine two societies. In the first, half the population have a life expectancy of 80 years, while the other half lives to be 70 . In the second society, everybody has a life expectancy of 60 years. It seems reasonable to say that, other things being equal, we should prefer the distribution of health in the first society, for even the worst-off enjoy higher life expectancies than anyone in the second society. In the spirit of the difference principle, then, we might hold that justice requires that the health of the worst-off be improved as much as possible, even if it entails overall inequality.

Yet this might be too quick. One reason for resisting the levelling down objection is that, in practical terms, aiming for equality might not lead to levelling down, for perhaps in the domain of health there is no trade-off between what economists call

47 See Parfit 2000: 98. 
'equity' and 'efficiency'. This is in part an empirical claim, and I offer it only tentatively here. Much of the discussion on equality has focused on income, which has its own logic. Economists assert that income incentives can result in productivity gains that are advantageous for a society as a whole. Because Rawlsian contractors are aware of this economic principle, it is rational for them to tolerate income inequalities to benefit the worst-off. But it is not clear that this consideration applies to health in the same way. As Sudhir Anand rightly notes, 'inequalities in health do not directly provide people with similar incentives to improve their health from which society as a whole benefits. $^{48}$

So perhaps the reasons that tell against strictly equal incomes are irrelevant to the domain of health. But this point notwithstanding, I believe there is an independent and decisive reason not to insist on equalitarianism in health. Recall that health cannot be distributed directly, but only through its social determinants, among them income. As already discussed, income inequalities can lead to income gains for the worst-off, but they also lead to inequalities in health. There is some discussion in the empirical literature on the exact relationship between income inequality and health. According to some, inequalities in income and status are bad in absolute terms, not just for the health of the worst-off, but for everyone. This is quite a surprising finding: an average person in a society with a highly unequal distribution of income is less healthy than a somewhat poorer person in a more egalitarian society. ${ }^{49}$ Whether or not this so-called 'income-relativity thesis' is correct ${ }^{50}$ however, most observers agree that there is a socio-economic gradient in health, meaning that income inequalities are correlated with health inequalities. So on either view, insisting on an equalitarian distribution of health

\footnotetext{
48 Anand 2004: 17.

49 Wilkinson 1996: ch. 5.

${ }^{50}$ For critical views, see Subramanian and Kawachi 2004; Deaton 2011: 18-9.
} 
would require an equalitarian distribution of all other primary goods that affect health. This is clearly a radical conclusion, as we would then be sacrificing absolute levels of income for the worst-off in the name of equality in health. We should therefore only be willing to accept it if we think that health is indeed 'chief among all goods.'

It is at this conjunction that the internal dimension bleeds into the external dimension. If we insisted on strictly equal levels of (socially determined) health, we would in practice be saying that the distribution of all other goods which affect health (such as income or education) is subservient to the goal of health equity. I will try to show that this is an implausible view, and that therefore, by default, there can be just inequalities in health. But to show this we need to focus now on the external dimension of the distributive question. We must ask, that is, whether health is more important than other goods, and what reasons there could be to allow or reject trade-offs with them.

Let me begin with the common observation that people in their personal lives are often willing to sacrifice or risk their health for other things they hold dear. For instance, many people freely choose to move to highly polluted cities for employment opportunities, thereby increasing the risk of contracting respiratory diseases. Others engage in high-risk sports such as surfing or boxing simply for fun. We do not think that these trade-offs are irrational and we would certainly not insist on people refraining from making them. However, what is true of the personal life of an individual may not necessarily be true of the principles of justice that govern our social arrangements. Even though many people do not seem to value their health very highly, it would be unjust to deny them the fair share of primary goods (including the social bases of health) necessary to pursue whatever it is they value in life. Hence the fact that people are willing to sacrifice their health for other goods does not entail that society should 
do the same. ${ }^{51}$ After all, some people are also willing to give up their basic liberties: many do not make use of their right to vote, and presumably some would trade it for money if they could. Still we think that people should be assigned equal basic liberties, irrespective of how they choose to make use of them.

So the question now is whether there is something about health that justifies treating it like the overriding value of basic liberty, rather than like income or wealth. One attractive view_-popular among philosophers and non-philosophers alike—-holds that the difference between health and money lies in the very nature of these goods: while money is merely an instrumental resource, health is intrinsically valuable. Consider, for instance, Susan Hurley's view:

Health is a distinctive kind of flourishing, with a specific natural character and basis, which seems to be a good in itself, in addition to being good for people. It is not just good for people to be healthy rather than unhealthy; it is also good in itself for there to be healthy people rather than unhealthy people. Compare: Can we also claim that it is not just good for people to have higher income levels, but also that it is good for there to be people with higher income levels rather than people with lower income levels? The latter claim seems to be only derivatively true, insofar as there are other things that are good in themselves that high income levels are a means to..$^{52}$

Whether health really has intrinsic value is an interesting question. If we stripped away all that is instrumentally valuable about being healthy — the avoidance of physical and

\footnotetext{
51 This suggests that, even if individuals bear some responsibility for the outcomes of their health-related choices, society has a prior responsibility to ensure that the background conditions under which these choices are made are sufficiently fair. This, in turn, presupposes a just distribution of the social bases of health and other primary goods. I develop these ideas in more detail in 'A Social Division of Responsibility for Health,' Les Ateliers de l'éthique/The Ethics Forum (forthcoming). 52 Hurley 2007: 332-3. Cf. Anand 2004; Sen 2004.
} 
mental pain, the ability to pursue of our goals and projects-what are we left with? While it is easy to see the intrinsic value of friendship, beauty or knowledge, it is not obvious to me that health is in itself a kind of flourishing. However, even if there is something intrinsically valuable about health, I think we should resist the temptation of assigning it priority for that reason. Hurley's view entails a form of impersonal perfectionism that sits uneasily with our general framework. The objection we dismissed in the previous section-namely that treating health as a primary social good would undermine a shared political conception of justice-resurfaces here with considerable more force. Liberal states should not promote values for their own sake. The worry of unacceptable perfectionism can only be defused if health is seen primarily as an instrumental all-purpose resource for the pursuit of individual conceptions of the good. While this does not mean that the state should refrain from promoting health, or that its value cannot be recognised by everyone, it tells against elevating health above other goods that we prize for what they enable us to achieve.

So if there is something that makes health special within a theory like justice as fairness, it seems it must either stem from some quality that makes it essential for the pursuit of our goals, or from its importance for our standing as equals in a fair system of social cooperation. I think there is something to be said for each of these points, although they will not take us all the way to the conclusion that health should never compete with other goods. Take the idea of equal standing: Daniel Hausman, for instance, argues that large inequalities in health change the way people relate to each other on a social level. Effectively, large health gaps 'render individuals vulnerable to domination by others and limit their domestic political voice. ${ }^{, 53}$ In extreme cases this

${ }^{53}$ Hausman 2012: 45. 
seems plausible enough. However, the same consideration applies also to large inequalities in income and wealth, so that if there is a difference between health and wealth in this regard, it seems to be merely a matter of degree.

Consider now the claim that health is special because it is essential for the pursuit of our goals in a way that money is not. This looks like a more promising strategy, I would argue, because health is a more fundamental kind of good. Serious diseases and impairments can come down to the existential question of bare survival. Now, being alive is not just another resource for the pursuit of our life plans, it is the absolute precondition. Difficult though it may be to pursue one's goals without money, it is simply impossible if one has died prematurely. And because rational persons have an interest in maintaining the conditions necessary to reappraise and revise their conceptions of the good, we must assign longevity great importance. This might be the kernel of truth in the old adage: 'health is not everything, but without health, everything is nothing.'

But even this argument has limits. First, it is important not to exaggerate the idea that longevity—or life itself, for that matter—is enormously valuable, for we are then presented with conclusions that resemble Pascal's wager. ${ }^{54}$ If longevity is infinitely valuable, any form of trade-off that implied even the tiniest risk of premature death ought to be disallowed. Surely this is too strong a view. After all, it would preclude the large majority of possible life plans that bear at least some risk of premature mortality, no matter how minor. Paradoxically, then, we would be treating continued life as an ab-

\footnotetext{
${ }^{54}$ Pascal famously argued that it is always rational to believe in God, no matter how unlikely his existence, for if he does exist, the disadvantage suffered in hell is infinitely bad.
} 
solute precondition for the pursuit of individual life plans, but there would be no possible life plans left to pursue. Although longevity is important, it cannot be everything that matters.

Moreover, the value of health is not limited to questions of life and death. We do not only want to live a normal life-span, but be healthy while we do. And if we look at health in terms of morbidity, it is not obvious that some diseases and impairments represent greater hindrances to our capacity to carry out a rational life plan than shortfalls in other primary goods. A mild cognitive disability or a mobility impairment, say, are not necessarily greater burdens than material poverty. We know, for instance, that moderate handicaps can be compensated through the provision of other goods, since the self-reported quality of life of many disabled people is not significantly below that of healthy people..$^{55}$ In this respect, health is not non-substitutable.

So let me try now to weave together the different strands of our discussion. How should the social bases of health be distributed? Because of the interdependence between health and other primary goods, an equalitarian social distribution of health would only be desirable if we thought that health enjoyed priority over all other goods. I think that we ought to reject this idea, even if there is some truth to the claim that longevity is fundamentally important for our ability to pursue a rational life plan, in a way that money, perhaps, isn't. But since there are no good reasons to categorically rule out trade-offs between health and other goods (external dimension), inequalities in health may be justified if the promotion of those other goods is deemed more important (internal dimension). In other words, health is among the goods governed by the difference principle, but there is no obvious ranking among these goods.

55 Hausman 2007: 55. 


\section{The Problem of Indexing}

From the point of view of theoretical parsimony, this leaves us in an unfortunate position. Since we have not rejected the possibility of trade-offs between the social bases of health and other goods, we are now confronted with the indexing problem that we hoped to avoid. Rawls had once proposed to take income and wealth as representative measures to identify the worst-off, assuming they were sufficiently correlated with the other primary goods. ${ }^{56}$ As we saw before, this was already then an oversimplification: if, for example, hierarchically organised companies are more productive, we are faced with trade-offs between income and power. In fact, even if all primary social goods were correlated, a solution to the indexing problem would still be required. After all, different institutional schemes might give us different combinations of income, wealth, power and authority, and we would need a way to decide among these alternative schemes. $^{57}$

Though this is a general problem with justice as fairness, adding the social bases of health to the index does not bring us any closer to a solution. As already discussed, income inequality can lead to higher absolute levels of income, but lower levels of health. Who are the worst-off, then: the poorest, or those with the smallest share of the social bases of health? If it proves impossible to find an answer, we might see here an argument in favour of seeking a different metric of justice, or even abandoning Rawls's theory to endorse, for instance, a view that treats different dimensions of (dis)advantage as separate and incommensurable spheres. ${ }^{58}$

56 Rawls 1999a: 83.

57 Arneson 1990: 445-6.

${ }^{58}$ E.g. Walzer 1983. However, even theories like Walzer's are faced with a similar problem. While within each sphere, they can advocate applying different principles of justice, they cannot tell us much about how a central government should allocate resources across different spheres, such as education, health, etc. See on this point Wolff and De-Shalit 2007: Ch 5. 
I can think of two possible solutions to the problem. The first would involve devising a new representative measure which in addition to income took into account some indicator of health. (Age-adjusted) mortality would be a plausible choice for both theoretical and practical reasons. While it is too rough a measure to capture everything that is important about health, it does capture longevity, which I argued must be assigned great moral importance. Incidentally, it is also easy to measure. Like income and wealth —and unlike power, authority and self-respect—we can obtain cardinal information about mortality, making it technically possible to construct a combined measure for longevity and income and wealth. Since longevity is also positively correlated with the other primary goods, this would moreover be a more robust measure than income alone.

There is, however, no obvious or natural way to establish the respective weights of the constitutive elements of a combined measure. While I argued that health should enjoy an important role in the index, any weighting we assign would be rather arbitrary at such an abstract level of theorising. This is what makes the second possible solution to the problem more attractive. This solution would involve keeping income as a rough provisional indicator to identify the worst-off and postponing the precise weighting of the index to a later legislative stage, where it is established through democratic means. This seems to have been Rawls's position, who argued that 'the weights for the index of primary social goods need not be established in the original position once and for all, and in detail, for every well-ordered society.' Rawls saw the implementation of his principles of justice proceeding along several stages, with the availability of information about the society in question gradually increasing. The highly abstract original position is characterised by a thick 'veil of ignorance.' Here, the constitutional essentials that guarantee the basic liberties, and the general form of the principles are decided. The 
details for the difference principle, in contrast, must be worked out at a later (legislative) stage, where the full range of economic and social facts about the society in question are known. ${ }^{59}$

And indeed, devising the index and assessing the trade-offs at stake requires much contextual social-scientific information. Consider, for instance, the relationship between health and power. According to Angus Deaton, the European ruling classes enjoyed virtually no health benefits over disadvantaged groups before 1750, implying that the observed correlation between power and health is a phenomenon that applies only to certain modern capitalist societies.$^{60}$ Or to take a more contemporary example, evidence for the 'income relativity thesis' — which holds that relative income inequality has absolute negative effects on population health—can be found in some states, but not others. ${ }^{61}$ It is precisely these sorts of information that are needed to establish the weightings of the primary goods governed by the difference principle.

If the problem of indexing is left to the legislative stage, it becomes a matter of democratic decision-making. This raises a question about the methods and criteria that citizens should use in establishing the index. It would go beyond the scope of this essay to propose an account of procedural justice or legitimacy, but however such an account is fleshed out, it is plausible to apply to it constraints that are defined at earlier stages of the process. Clearly, the priority of basic liberties and fair equality of opportunity represent the most fundamental constraints to a democratic process. But there are also other, perhaps less obvious limits to the weighing of primary goods. They stem from their role in securing our moral powers to have a sense of justice and pursue a conception of the good. Any trade-off between primary goods that undermined these powers

\footnotetext{
${ }^{59}$ Rawls 1999a: §31.

${ }^{60}$ Deaton 2011: 2.

61 Subramanian and Kawachi 2004.
} 
should be rejected. For instance, increasing income levels for the worst-off at the expense of their health would only be acceptable to the point where their moral power to pursue their life plans is undermined. When is that point reached? It seems hopeless to expect a clear-cut answer, but perhaps we do not need one. Rawls himself was pragmatic. In devising the index, he suggested, 'we admittedly rely upon intuitive estimates. But this cannot be avoided entirely. ${ }^{62}$

Needless to say, there remain some open questions, and the approach sketched here is by its very nature indeterminate. This might not be satisfying if one believes that there is a morally correct answer to all distributive questions, and that the appeal to procedural justice is but a second-best solution in the face of epistemic uncertainty. But I would resist this view. Since duties of justice are binding, the more we specify the demands of justice, the less room there is for a political community to express its own priorities. And from this point of view, a theory that left no space to democratic decision-making about weighing incommensurable social goals would strike me as less plausible than the alternative. To be sure, nothing in the democratic approach to the indexing problem suggests that we should be willing to accept large inequalities in health (or any other good, for that matter). But it does presuppose that there is a range of reasonable views which may be implemented in a legitimate process.

62 Rawls 1999a: 80. 


\section{Conclusion}

Health and illness, I argued in this paper, must in some way or another figure into our thinking about distributive justice. Although health may not necessarily be more important than other goods, it does raise some significant and distinct questions which need to be addressed explicitly in a general theory of distributive justice.

Since I set out by examining the most important contemporary account of justice in health-Norman Daniels's theory-I want to close by briefly reflecting on the differences and similarities between it, and the alternative proposal I have put forward here. Among the many points of agreement, there are two which are worth highlighting. The first relates to how Daniels links the research on the social determinants of health to Rawls's theory of justice. Daniels's work is pioneering in recognising that justice in health is not limited to questions of healthcare. On the contrary, the way our most basic social arrangements affect the level and distribution of health in a population must be central to a theory of justice. A second affinity consists in the way Daniels explains the significance of health in terms of its instrumental value for the pursuit of our life plans. It is as an instrumental resource, and not as an objective value in itself, that we can think of health, and the fairness of its distribution, as a shared political goal in a pluralistic society.

But despite all there is to admire about Daniels's work, I believe we can make progress by abandoning some key tenets of his account. The first is the way he subsumes the value of health under the principle of fair equality of opportunity. I argued that this move comes at a high cost: not only does Daniels's interpretation of said principle undermine Rawls's original rationale for it, it also creates an internal tension in the theory once the social determinants of health are regulated through it. A more plausible alternative, I argued, is to express the instrumental significance of health by 
treating it directly as a primary good. After all, furthering the opportunity to pursue our life plans is the purpose of all primary goods, and now that we know that our opportunities to be healthy are heavily shaped by the basic structure of society, this expansion of Rawls's original index seems a natural suggestion.

A second difference is this. Daniels's is what we may call a unified theory of justice in health: the importance of distributing the social determinants of health fairly, and our duty to provide universal access to medical care are both explained through appeal to the same value: fair equality of opportunity. My view, in contrast, is that these two duties may rest on different rationales. The problem of justice in the distribution of the social bases of health can be seen through the lens of a Rawlsian imperative to allocate the benefits and burdens of social cooperation fairly, or so I argued. Our duty to attend to all medical needs, regardless of aetiology, may be justified on different grounds.

There is, finally, a third important difference between the two approaches. One implication of rejecting Daniels's appeal to the opportunity principle is that we also reject his claim that health is 'special,' a claim derived from the lexical priority of said principle. In putting the social bases of health alongside the other primary goods, we bring out into the open questions about priorities and trade-offs in the pursuit of disparate social aims. These questions are theoretically difficult. But I think it is an advantage to be able to address them explicitly, instead of sweeping them under the carpet by thinking of health as a special good. Indeed, Daniels himself has often recognised that the promotion and protection of health cannot always override other social 
goals, and that reasonable people may disagree on these questions. ${ }^{63}$ This view is certainly more consistent with the general framework I have suggested. Although this framework implies some loss in theoretical parsimony, my hope is that it is offset by a gain in theoretical cogency.

\section{References}

Anand, Sudhir (2004). 'The Concern for Equity in Health,' in Sudhir Anand, Fabienne Peter and Amartya Sen (eds.) Public Health, Ethics and Equity (Oxford: Oxford University Press), pp. 15-20.

Anderson, Elizabeth (1999). 'What Is the Point of Equality?' Ethics 109(2): 287-337.

Arneson, Richard (1990). 'Social Primary Goods Reconsidered,' Nô̂s 24(3): 429-54.

Arrow, Kenneth (1973). 'Some Ordinalist-Utilitarian Notes on Rawls's Theory of Justice by John Rawls,' Journal of Philosophy 70(9): 245-63.

Birn, Anne-Emmanuele (2011). 'Adressing the Social Determinants of Health. The Key Health Ethics Imperative of our Times,' in Solomon Benatar \& Gillian Brock (eds.) Global Health and Global Health Justice (Cambridge: Cambridge University Press), pp. 37-51.

Black, Douglas Sir et al. (1980). 'The Black Report,' in Peter Townsend \& Nick Davidson (eds.) Inequalities in Health (London: Penguin).

Buchanan, Allen (1984). 'The Right to a Decent Minimum of Healthcare,' Philosophy \& Public Affairs 13(1): 55-78.

Daniels, Norman (2007). Just Health. Meeting Health Needs Fairly (Cambridge: Cambridge University Press).

Daniels, Norman (1985). Just Healthcare (Cambridge: Cambridge University Press).

Daniels, Norman, Bruce Kennedy and Ichiro Kawachi (2004). 'Health and Inequality, or, Why Justice is Good for Our Health,' in Sudhir Anand, Fabienne Peter and Amartya Sen (eds.) Public Health, Ethics and Equity (Oxford: Oxford University Press), pp. 63-91.

${ }^{63}$ See, most notably, his work on 'accountability for reasonableness.' E.g. Daniels 2008: Ch. 4. 
Daniels, Norman and James Sabin (1997). 'Limits to Healthcare: Fair Procedures, Democratic Deliberation and the Legitimacy Problem for Insurers,' Philosophy \& Public Affairs 26(4): 303-50.

Deaton, Angus (2011). 'What Does the Empirical Evidence Tell Us About the Injustice of Health Inequalities?' Princeton Working Paper Series. Available at: http://dx.doi.org/10.2139/ssrn.1746951 (accessed 04/08/2013).

Dworkin, Ronald (2000). Sovereign Virtue: The Theory and Practice of Equality (Cambridge MA: Harvard University Press).

Dworkin, Ronald (1993). 'Justice in the Distribution of Healthcare', McGill Law Journal 38(4): 884-98.

Freeman, Kathleen (1971). Ancilla to the Pre-Socratic Philosophers (Oxford: Blackwell).

Green, Ronald (1976). 'Healthcare and Justice in Contract Theory Perspective,' in Robert Veatch and Roy Branson (eds.) Ethics in Health Policy (Cambridge, MA: Ballinger Publishing Company), pp. 111-26.

Greven, Corina et. al. (2009). 'More than Just IQ. School Achievement Is Predicted by Self Perceived Abilities-But for Genetic Rather Than Environmental Reasons,' Psychological Science 20: 753-62.

Hausman, Daniel (2012). 'What's Wrong with Global Health Inequalities?', in Lenard, Patti and Christian Straehle (eds.) Health Inequalities and Global Justice (Edinburgh: Edinburgh University Press), pp. 34-51.

Hausman, Daniel (2007). 'What's Wrong with Health Inequalities?' The Journal of Political Philosophy 15(1): 46-66.

Hurley, Susan (2007). 'The 'What' and the 'How' of Distributive Justice and Health,' in Nils Holtung and Kasper Lippert-Rasmussen (eds.) Egalitarianism. New Essays on the Nature and V alue of Equality (Oxford: Oxford University Press), pp. 308-34.

Kamm, Frances (1993). Morality, Mortality. Vol. 1: Death and Whom to Save from It (New York: Oxford University Press).

Kniess, Johannes (forthcoming). 'A Social Division of Responsibility for Health,' Les Ateliers de l'éthique/The Ethics Forum (forthcoming).

Marmot, Michael (2007). 'Achieving Health Equity: From Root Causes to Fair Outcomes,' The Lancet 370: 1153-63.

Marmot, Michael (2004). Status Syndrome: How Your Social Standing Directly Affects Your Health and Life Expectany (London: Bloomsbury). 
Marmot, Michael and Richard Wilkinson (1999): Social Determinants of Health (Oxford: Oxford University Press).

Nagel, Thomas (1997). 'Justice and Nature,' Oxford Journal of Legal Studies 17(2): 30321.

Office for National Statistics (2016). 'Healthy Life Expectancy at Birth and Age 65 by Upper Tier Local Authority and Area Deprivation: England, 2012 to 2014' Available at: https://www.ons.gov.uk/peoplepopulationandcommunity/healthandsocialcare/healthandlifeexpectancies/bulletins/healthylifeexpectancyatbirthandage65byuppertierlocalauthorityandareadeprivation/england2012to2014 (accessed 10/01/2017).

Parfit, Derek (2000). 'Equality or Priority?' in Matthew Clayton and Andrew Williams (eds.) The Ideal of Equality (Basingstoke: Palgrave Macmillan), pp. 81-125.

Peter, Fabienne (2004). 'Health Equity and Social Justice', in Sudhir Anand, Fabienne Peter and Amartya Sen (eds.) Public Health, Ethics and Equity (Oxford: Oxford University Press), pp. 93-106.

Pogge, Thomas (2004). 'Relational Conceptions of Justice: Responsibility for Health Outcomes,' in Sudhir Anand, Fabienne Peter and Amartya Sen (eds.) Public Health, Ethics and Equity (Oxford: Oxford University Press), pp. 135-62.

Rawls, John (2001). Justice as Fairness. A Restatement (Cambridge MA: Harvard University Press).

Rawls, John (1999a). A Theory of Justice (Cambridge MA: Harvard University Press).

Rawls, John (1999b). Collected Papers. ed. Samuel Freeman (Cambridge MA: Harvard University Press).

Rawls, John (1993). Political Liberalism (New York: Columbia University Press).

Segall, Shlomi (2009). Health, Luck and Justice (Princeton: Princeton University Press).

Sen, Amartya (2004). 'Why Health Equity?' in Sudhir Anand, Fabienne Peter and Amartya Sen (eds.) Public Health, Ethics and Equity (Oxford: Oxford University Press), pp. 21-33.

Sen, Amartya (1980). 'Equality of What?' in Sterling McMurrin (ed.) The Tanner Lectures on Human V alues, Vol. I (Salt Lake City, University of Utah Press,), pp. 353-69.

Sreenivasan, Gopal (2007). 'Health Care and Equality of Opportunity,' Hastings Center Report 37(2): 21-31.

Stern, Lawrence (1981). 'Opportunity and Healthcare: Criticisms and Suggestions,' The Journal of Medicine and Philosophy 8: 339-61. 
Subramanian, S. V. and Ichiro Kawachi (2004). 'Income Inequality and Health: What Have We Learned So Far?’ Epidemiologic Reviews 26(1): 78-91.

Veatch, Robert (1999). 'Justice, the Basic Social Contract and Healthcare,' in Tom Beauchamp and LeRoy Walters (eds.) Contemporary Issues in Bioethics, 5th Edition (Belmont, CA: Wadsworth), pp. 368-74.

Venkataparum, Sridhar (2011). Health Justice (Cambridge: Polity Press).

Walzer, Michael (1983). Spheres of Justice (New York: Basic Books).

WHO (2013). Constitution of the World Health Organization. Available at: http://www.who.int/governance/eb/constitution/en/ (accessed 23/08/2013).

WHO Europe (2003). Social Determinants of Health. The Solid Facts. 2nd Edition (Copenhagen: $\mathrm{WHO})$.

Wikler, Daniel (1978). 'Paternalism and the Mildly Retarded,' Philosophy \& Public Affairs 8(4): 377-92.

Wilkinson, Richard (2001). Mind the Gap: Hierarchies, Health and Human Evolution (New Haven: Yale University Press).

Wilkinson, Richard (1996). Unhealthy Societies. The Afflictions of Inequality (London: Routledge).

Wilson, James (2009). 'Not So Special After All? Daniels and the Social Determinants of Health,' Journal of Medical Ethics 35: 3-6.

Wolff, Jonathan and Avner De-Shalit (2007). Disadvantage (Oxford: Oxford University Press). 